\title{
Determination of Sulfide with Acidic Permanganate Chemiluminescence for Development of Deep-sea in-situ Analyzers
}

\author{
Keiichi Fujimori, ${ }^{* \dagger}$ Kenta Tsujimoto, ${ }^{*}$ Takayo Moriuchi-Kawakami,* Yasuhiko Shibutani,* \\ Masato UedA, ${ }^{* *}$ Takahiko Suzue, ${ }^{* *}$ Hideshi KIMOTO, ${ }^{* *}$ and Kei OKAMURA*** \\ *Department of Applied Chemistry, Faculty of Engineering, Osaka Institute of Technology, \\ 5-16-1 Omiya, Asahi, Osaka 535-8585, Japan \\ **Kimoto Electric Co. Ltd., 3-1 Funahashi, Ten-noji, Osaka 543-0024, Japan \\ ***Center for Advanced Marine Core Research, Kochi University, B200 Monobe, Nankoku, \\ Kochi 783-8502, Japan
}

\begin{abstract}
A new chemiluminescence method is proposed for the determination of sulfide in seawater based on the chemiluminescence reaction between sulfide and an acidic permanganate solution. 3-Cyclohexylaminopropanesulfonic acid was used as a chemiluminescence enhancer. By use of this method, $1-150 \mu \mathrm{M}$ of sulfide could be determined in artificial seawater. The limit of detection was $0.17 \mu \mathrm{M}$ sulfide. We investigated the effects of salinity, water temperature, and interfering chemicals such as heavy-metal ions and organic matter. In addition, natural seawater spiked with sulfide was analyzed. The results showed that the CL method could be applied to a deep-sea sulfide analyzer.
\end{abstract}

(Received August 23, 2010; Accepted December 8, 2010; Published February 10, 2011)

\section{Introduction}

The composition of the main inorganic constituents of seawater is constant, except in particular areas, e.g., coastal areas. The conservative elements are chlorine, sodium, sulfur, and magnesium. Sulfur is the element with the third highest concentration $(29 \mathrm{mM})$ in seawater, and most sulfur in seawater is dissolved as sulfates. ${ }^{1}$ The other sulfur species cannot be found in an aerobic environment because they are easily oxidized. However, sulfide is present in anaerobic environments and hot springs. In deep seas, hydrothermal vents found near volcanically active areas emit sulfides in several millimolar concentrations. Sulfides are one of the most important species in deep-sea environments. Unique biological communities are found around submarine hydrothermal vents, and these communities derive energy from the metabolic oxidation of sulfides. ${ }^{2}$ Furthermore, sulfides can control trace metal ions in seawater because many metal sulfides have poor solubility.

The development of an in-situ analyzer is necessary for the exact measurements of sulfide concentrations because sulfides are volatile and show high reactivity with dissolved oxygen. Colorimetric $^{3-5}$ and electrochemical ${ }^{3,4,6}$ methods have been employed in in-situ deep-sea sulfide analyzers. The colorimetric method has several disadvantages for the in-situ analysis of deep seawater: a low sulfide detection limit $(1 \mu \mathrm{M})$, decreasing sensitivity, and increasing response times at low temperature. ${ }^{3}$ It is difficult to monitor deep seawater by electrochemical methods because electrodes show serious hysteresis effects

† To whom correspondence should be addressed.

E-mail: fujimori@chem.oit.ac.jp under high pressures.

Only the geochemical anomaly monitoring system (GAMOS) that uses a hydrogen peroxide-luminol chemiluminescence (CL) method has been successfully used to obtain the concentration profiles of chemical species in submarine hydrothermal fields. ${ }^{7-10}$ CL methods are suitable for application to in-situ analyzers because the CL apparatus has a simple mechanism and a rapid response. A few CL methods for sulfide analysis using luminol have been reported, ${ }^{11-13}$ and CL reactions with oxidants have also been reported. ${ }^{14-18}$ However, CL methods using luminol with gaseous separation cannot be applied to in-situ analyzers. The CL method using permanganate is a simple system. ${ }^{18}$ Permanganate has also been used for the analysis of organic substances in seawater. ${ }^{19}$ We examined the suitability of the CL method with permanganate for use in in-situ analyzers for hydrothermal field.

\section{Experimental}

\section{Reagents}

Purified water was obtained by ion exchange and distillation. All purchased chemicals were of special grade. A permanganate solution $\left(1.0 \times 10^{-4} \mathrm{M}\right)$ was prepared by dissolving potassium permanganate in water in sulfuric acid with a concentration of $1.0 \times 10^{-2} \mathrm{M}$. A 3-cyclohexylaminopropanesulfonic acid (CAPS) solution $(20 \mathrm{mM})$ was prepared by dissolving CAPS in water. Artificial seawater was prepared by dissolving $\mathrm{NaCl}$ (23.477 g), $\mathrm{MgCl}_{2}$ (4.981 g), $\mathrm{Na}_{2} \mathrm{SO}_{4}(3.912 \mathrm{~g}), \mathrm{CaCl}_{2}(1.120 \mathrm{~g}), \mathrm{KCl}$ $(0.660 \mathrm{~g})$, and $\mathrm{NaHCO}_{3}(0.192 \mathrm{~g})$ in water $(1 \mathrm{~L})$. A sulfide solution $(10 \mathrm{mM})$ was prepared by dissolving sodium sulfide nonahydrate $(0.240 \mathrm{~g})$ in water $(100 \mathrm{~mL})$. Standard solutions 


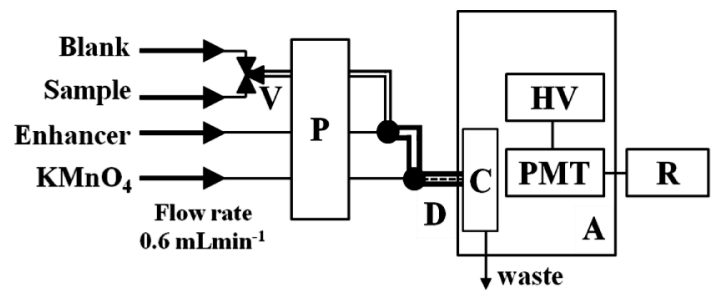

(A)CL analyzer(EN-21); (C) CL flow cell; (D) Double concentric tube; (HV) High voltage; (P) Pump; (PMT)Photomultiplier tube; (R)Recorder; (V)Valve

(a)

\section{Entrance}

(b)

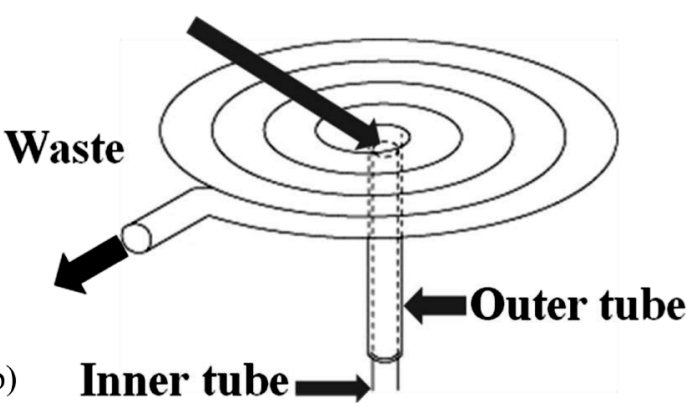

Fig. 1 Schematic representation of CL detection system. (a) CL analyzing system and (b) CL flow cell.

( $1-1000 \mu \mathrm{M})$ were prepared for diluting the sulfide solution with artificial seawater before use. Natural seawater samples from Ogasawara and Izu (Nazeme 397) were purchased from Ogasawara Kaisou Kenkyuukai and Blue 3, respectively.

\section{Apparatus and procedures}

The CL intensities were measured using an EN-21 CL analyzer (Kimoto Electric Co., Ltd., Osaka, Japan) fitted with an H6780 photomultiplier tube (PMT; Hamamatsu Photonics, Shiuzoka, Japan). A scroll CL reaction cell (Pyrex glass; diameter, $3 \mathrm{~cm}$; i.d., $1.3 \mathrm{~mm}$; volume, $0.23 \mathrm{~mL}$ ) was set up in our laboratory. Super Coon Ace tubing (i.d., $2 \mathrm{~mm}$; Utsunomiya Seisaku Co., Ltd., Tochigi, Japan) and a peristaltic pump (Master flex pump, Cole-Parmer, Vernon Hills, IL) were used for transporting the solutions. The pump was connected to the other units (solution vessel, CL reaction cell, etc.) using perfluoroalkoxy (PFA) tubing (i.d., $1 \mathrm{~mm}$; Iwase Co., Kanagawa, Japan). A schematic representation of the CL detection system is shown in Fig. 1. The acidic permanganate solution ( $\mathrm{pH} 2.0)$, the CAPS solution ( $\mathrm{pH} 5.5)$, and blank water ( $\mathrm{pH}$ 8.0) were continuously pumped into the $\mathrm{CL}$ analyzer. The flow rates of all the solutions were $0.6 \mathrm{~mL} / \mathrm{min}$. Before entering the $\mathrm{CL}$ analyzer, the CAPS solution and blank water were mixed at a T-shaped joint. The mixed solution ( $\mathrm{pH}$ 7.9) was pumped through the outer part of a double concentric tube. In the CL reaction cell, the solution mixture was mixed with the acidic permanganate solution through the inner part. The mixing point was set at the center, i.e., the inlet (entrance) of the scroll CL reaction cell. When the manual valve was switched from the blank to the sample line, the sample solution was directed to the $\mathrm{CL}$ reaction cell. The CL emissions were measured using the PMT operated at $-850 \mathrm{~V}$. The unit relative CL intensity was measured using a $50 \mu \mathrm{M}$ standard sulfide solution under optimum conditions. The analytical value was the average of
Table 1 Effect of enhancer on relative CL intensity of sample solutions

\begin{tabular}{lcc}
\hline \multirow{2}{*}{$\begin{array}{c}\text { Enhancer } \\
\text { solution }\end{array}$} & \multicolumn{2}{c}{ Sample solution } \\
\cline { 2 - 3 } & Artificial seawater & Sulfide solution $(50 \mu \mathrm{M})$ \\
\hline \multirow{2}{*}{ Water } & ND & ND \\
CAPS & ND & 0.88 \\
Quinine & ND & 0.08 \\
Papaverine & ND & 0.08 \\
Riboflavin & ND & ND \\
\hline
\end{tabular}

ND: Not detected.

more than three measurements.

The $\mathrm{pH}$ was measured using an F-52pH meter (Horiba Ltd., Kyoto, Japan).

\section{Results and Discussion}

\section{Enhancer selection}

Our CL analyzer could not obtain a signal from the mixture of permanganate and sulfide solutions. Furthermore, CL could not be detected even after the addition of riboflavin, which has been reported to be a CL enhancer. ${ }^{18,20}$ Few enhancers have been developed for the sulfide-permanganate $\mathrm{CL}$ reaction. In contrast, many enhancers have been developed for sulfides. ${ }^{21-23}$ The enhancers investigated for our system were papaverine, quinine, CAPS, and riboflavin. CL emissions were examined for a mixture of a $10 \mathrm{mM}$ enhancer solution and a $100 \mathrm{mM}$ permanganate solution in $10 \mathrm{mM}$ sulfuric acid. Artificial seawater was then fed into the sample solution line of the CL analyzer. No CL was detected with any of the enhancers. When $50 \mu \mathrm{M}$ sulfide solution was fed into the sample line, CL emissions were obtained using CAPS, quinine, and papaverine. CAPS was selected as the enhancer because it had the strongest effect. These results are shown in Table 1.

\section{Optimum conditions}

A flow rate of $0.6 \mathrm{~mL} / \mathrm{min}$ for all the solutions was chosen as the best maximum flow rate for use with the pump. Relatively high flow rates consume more electricity and produce a relatively high volume of waste. A study was conducted to obtain the optimum acidity and concentration of potassium permanganate and the concentration of CAPS. Artificial seawater containing sulfide $(50 \mu \mathrm{M})$ was used as the standard solution. The maximum CL peak was obtained using the $100 \mu \mathrm{M}$ permanganate solution. The CL intensity increased gradually to the maximum valve at a $10 \mathrm{mM}$ sulfuric acid concentration and then decreased at higher concentrations of sulfuric acid. A constant CL intensity was obtained when the CAPS concentration was around $20 \mathrm{mM}$.

\section{CL flow cell}

The material and the shape of the CL flow cell influence the CL intensity. ${ }^{24}$ The effects of these factors on the CL cell are shown in Table 2. The mixing position was studied using a Pyrex spiral cell. The strongest CL emissions were obtained by mixing the solutions at the cell entrance. The further the mixing point was from the cell entrance, the lower was the CL intensity. To compare different cell shapes, an L-shaped quartz cell was used. The CL intensity of the L-shaped cell was weaker than that of the spiral cell because the CL emitting area of the 
Table 2 Comparison of various CL reaction cell materials, designs, and mixing positions

\begin{tabular}{|c|c|c|c|c|}
\hline \multicolumn{3}{|c|}{ CL cell } & \multirow{2}{*}{$\begin{array}{l}\text { Mixing } \\
\text { position } \\
\text { from the } \\
\text { entrance }\end{array}$} & \multirow{2}{*}{$\begin{array}{l}\text { Relative } \\
\text { CL } \\
\text { intensity }\end{array}$} \\
\hline $\begin{array}{l}\text { Material and } \\
\text { design }\end{array}$ & $\begin{array}{c}\text { Volume/ } \\
\mathrm{mL}\end{array}$ & $\begin{array}{l}\text { Diameter/ } \\
\mathrm{cm}\end{array}$ & & \\
\hline \multirow[t]{3}{*}{ Pyrex/spiral } & \multirow[t]{3}{*}{0.23} & \multirow[t]{3}{*}{3} & At the entrance & $1.00 \pm 0.05$ \\
\hline & & & $1 \mathrm{~cm}$ before & $0.91 \pm 0.02$ \\
\hline & & & $3 \mathrm{~cm}$ before & $0.81 \pm 0.10$ \\
\hline Quartz/L shaped & 0.08 & $3.5^{\mathrm{a}}$ & \multirow{6}{*}{ The entrance } & $0.50 \pm 0.01$ \\
\hline PTFE/spiral & 0.12 & 2 & & $0.59 \pm 0.03$ \\
\hline PTFE/spiral & 0.23 & 3 & & $0.75 \pm 0.03$ \\
\hline PFA/spiral & 0.12 & 2 & & $0.75 \pm 0.03$ \\
\hline PFA/spiral & 0.23 & 3 & & $0.88 \pm 0.03$ \\
\hline Super Coon Ace/spiral & 0.23 & 2 & & $0.82 \pm 0.04$ \\
\hline
\end{tabular}

a. The length of the side facing PMT.

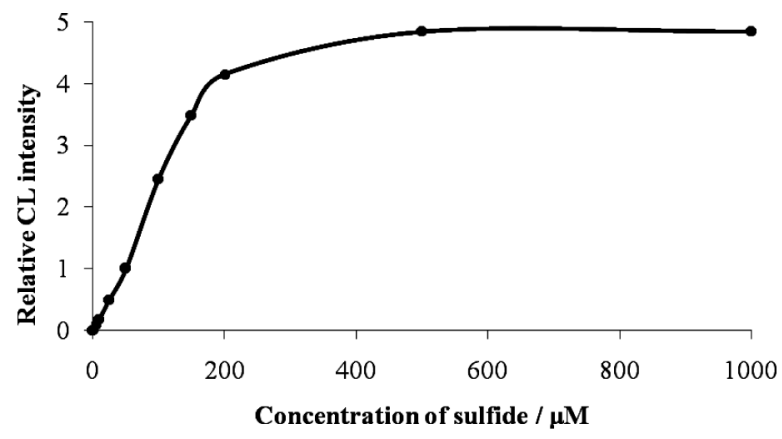

Fig. 2 Calibration curve for sulfide determination by CL method.

L-shaped cell was small. A Pyrex cell resulted in stronger CL emissions than cells made of other materials.

\section{Calibration curve}

Figure 2 shows the calibration curves for sulfide on the basis of the CL reaction. At approximately $150 \mu \mathrm{M}$, the calibration curve began to plateau. The linear range of the calibration curve was $0-150 \mu \mathrm{M}$ (correlation coefficient: 0.995). The limit of detection calculated from $3 \sigma$ of a blank was $0.17 \mu \mathrm{M}$, and the relative standard deviation was $2.6 \%$ at $50 \mu \mathrm{M} \quad(n=10)$. Deep-sea hydrothermal fluids contain several millimoles of sulfide per kilogram. ${ }^{25,26}$ Like smoke from an industrial chimney, the concentrations of species in a hydrothermal plume decrease to dilute and form precipitations of heavy metal ions with a further hydrothermal vent. Johnson et al. reported a method for measuring $0-100 \mu \mathrm{M}$ sulfide at clumps of vent animals in a hydrothermal field; the vents were located at intervals of $50-100 \mathrm{~m}$ in this field. ${ }^{4} \mathrm{An}$ area with a radius of a few hundred meters around a hydrothermal vent would be observed by using the sulfur CL analyzer.

\section{Effect of chloride ion on CL intensity}

The salinity of seawater is $c a .3 .5 \%$. However, the salinity changes in hydrothermal fluids. ${ }^{26}$ The effect of salinity on CL intensity was also studied. The salinity of the sulfide solution was changed by the addition of appropriate amounts of artificial seawater. The CL intensity was constant with changing salinity up to $3.5 \%$ investigated. Therefore, the CL method is suitable for analyzing seawater in hydrothermal fields.
Table 3 CL intensities of heavy metals and organic matter

\begin{tabular}{lcc}
\hline \multicolumn{1}{c}{ Sample } & Concentration & Relative CL intensity \\
\hline $\mathrm{Fe}(\mathrm{II})$ & $500 \mu \mathrm{M}$ & $\mathrm{ND}$ \\
$\mathrm{Fe}(\mathrm{III})$ & & $\mathrm{ND}$ \\
$\mathrm{Mn}(\mathrm{II})$ & & $\mathrm{ND}$ \\
$\mathrm{Cu}(\mathrm{II})$ & & $\mathrm{ND}$ \\
$\mathrm{Zn}(\mathrm{II})$ & & $\mathrm{ND}$ \\
$\mathrm{Cu}(\mathrm{II})$ & & $\mathrm{ND}$ \\
$\mathrm{Ni}(\mathrm{II})$ & $1.7 \mu \mathrm{M}$ & $\mathrm{ND}$ \\
Pyrogallol & $1.7 \mu \mathrm{M}$ & $\mathrm{ND}$ \\
Ascorbic acid & $1.4 \mu \mathrm{M}$ & $\mathrm{ND}$ \\
Salicylic acid & $4.2 \mathrm{mg} \mathrm{O} / \mathrm{L}$ & $\mathrm{ND}$ \\
Yodo River & $12 \mathrm{mg} \mathrm{O} / \mathrm{L}$ & 0.05 \\
"Wando" pool of Yodo & & \\
\hline
\end{tabular}

ND: Not detected.

Interference with CL by heavy-metal ions and organic matter Hydrothermal fluids also have high concentrations of heavy-metal ions. ${ }^{25,26}$ It has been reported that some metal ions enhance CL emissions. ${ }^{19,27}$ Most heavy-metal ions react with sulfide to form insoluble precipitation. It is impossible to study the effects of heavy-metal ions on sulfide CL. Organic materials in seawater cause permanganate CL emissions. ${ }^{19}$ The presence of organic carbon in hydrothermal fields has been reported. Dissolved organic carbon (DOC) concentrations in the range $10-50 \mu \mathrm{M}$ have been reported in hydrothermal fields. ${ }^{28}$ The CL intensities of some heavy-metal ions and organic matter with acidic permanganate were measured. Some organic chemicals cause CL by reaction with acidic permanganate..$^{29}$ Table 3 shows the CL intensities with heavy-metal ions and organic chemicals. The concentrations of the organic chemicals were $10 \mu \mathrm{M}$ of the theoretical total organic carbon (TOC) content. CL emissions were not detected for any of the ions or organic chemicals. According to a previous report, organic chemicals cause strong CL emissions at $c a .740 \mathrm{~nm} .{ }^{29}$ The CL analyzer could not detect the CL intensity of the organic chemicals because the sensitivity of the PMT used was low against the high-wavelength light. In contrast, the enhanced CL obtained with CAPS was emitted at $c a .480 \mathrm{~nm}$. When CAPS was added, the CL reaction of sulfide with permanganate was found at the abovementioned wavelength. ${ }^{15}$ Water from Yodo River and the Wando pool near the river were selected as sources of natural water rich in organic substances. The $\mathrm{COD}_{\mathrm{Mn}}$ values of the two river waters were measured using the method specified by JIS. ${ }^{30}$ To obtain the CL intensities, salts were added to the waters at the same concentration as in seawater. The CL intensities obtained were low despite the fact that the organic concentrations were higher than those in hydrothermal seawater; therefore, organic substances in hydrothermal fields do not interfere with the analytical method.

\section{Temperature effects}

Deep seawater remains cool (a few degrees Celsius). ${ }^{4,7}$ It is reasonable to assume that $\mathrm{CL}$ is dependent on temperature. ${ }^{7-9,29}$ The effects of temperature on CL for $50 \mu \mathrm{M}$ sulfide were investigated. The CL intensity did not change over the investigated range from 5 to $30^{\circ} \mathrm{C}$. The activation energy of the CL reaction was very low. This implies that the CL method was stable with respect to changes in the temperature.

Analysis of spiked seawater samples

Spiked seawater samples were analyzed in order to confirm 
Table 4 Recovery (\%) of CL intensity by spiking seawater samples with sulfide

\begin{tabular}{lrrr}
\hline \multirow{2}{*}{ Sample } & \multicolumn{3}{c}{ Spiked concentration of sulfide/ $\mu \mathrm{M}$} \\
\cline { 2 - 4 } & \multicolumn{1}{c}{25} & \multicolumn{1}{c}{50} & \multicolumn{1}{c}{100} \\
\hline Sesoko & $100 \pm 1.0$ & $94.0 \pm 3.0$ & $95.6 \pm 3.0$ \\
Maizuru & $105 \pm 5.0$ & $98.3 \pm 1.5$ & $101 \pm 1.2$ \\
Katuura & $96.0 \pm 3.6$ & $94.7 \pm 1.3$ & $94.4 \pm 1.2$ \\
Izumo & $96.3 \pm 4.4$ & $94.6 \pm 1.8$ & $102 \pm 5.3$ \\
Ogasawara & $99.6 \pm 0.7$ & $104 \pm 3.6$ & $94.4 \pm 4.0$ \\
Izu & $98.5 \pm 2.6$ & $102 \pm 4.6$ & $101 \pm 2.4$ \\
\hline
\end{tabular}

the feasibility of the CL method for determining the sulfide content in seawaters. Table 4 shows the recovery of sulfide. Seawater samples from six locations (Sesoko, Okinawa; Maizuru, Kyoto; Katuura, Wakayama; Izumo, Shimane; Ogasawara, Tokyo; Izu, Shizuoka) were measured by using the CL method. No sulfide was found in any of the seawater samples. Sulfide was added to the seawater to yield concentrations of 25,50 , and $100 \mu \mathrm{M}$, and the recoveries were calculated from the CL intensities. The relative standard deviation $(\%)$ for the determination of standard sulfide solutions was $1.0,2.6$, and $3.9 \%$ for 25,50 , and $100 \mu \mathrm{M}$ solutions, respectively. All recoveries were close to $100 \%$. No matrix interference was found.

\section{Conclusion}

The CL method with permanganate is suitable for the determination of deep-sea sulfides. In future, a pressure- and water-resistant analyzer will be developed. The development of an in-situ analyzer for sulfides should be easy because the same CL method is used as that for GAMOS. The present method is simpler than those previously employed in GAMOS. ${ }^{7-10}$ The new analyzer is expected to provide new information on hydrothermal fields.

\section{References}

1. T. Fu, "Environmental Chemistry: Essentials of Chemistry for Engineering Practice", 1999, Vol. 4A, Prentice-Hall, Upper Saddle River, 414.

2. T. M. McCollom, Deep Sea Res. I, 2000, 47, 85.

3. K. S. Johnson, C. L. Beehler, and C. M. Sakamoto-Arnold, Anal. Chim. Acta, 1986, 179, 245.

4. K. S. Johnson, C. L. Beehler, C. M. Sakamoto-Arnold, and J. J. Childress, Science, 1986, 231, 1139.

5. T. Gamo, H. Sakai, E. Nakayama, K. Ishida, and H. Kimoto, Anal. Sci., 1994, 10, 843.

6. T. Sugiyama, M. Hatta, K. Okamura, M. Houjyou, T.
Suzue, H. Kimoto, T. Kioto, T. Hinoue, T. Fukushima, and T. Fujii, in Book of Abstracts of the 57th Annual Meeting of Japan Society for Analytical Chemistry, 2006, Fukuoka, Japan, 200.

7. K. Okamura, H. Kimoto, K. Saeki, J. Ishibashi, H. Obata, M. Maruo, T. Gamo, E. Nakayama, and Y. Nozaki, Mar. Chem., 2001, 76, 17.

8. K. Okamura, Nippon Kaisui Gakkaishi, 2004, 58, 348.

9. K. Okamura, H. Hatanaka, H. Kimoto, M. Suzuki, Y. Sohrin, E. Nakayama, T. Gamo, and J. Ishibashi, Geochem. J., 2004, 38, 635.

10. T. Doi, M. Takano, K. Okamura, T. Ura, and T. Gamo, $J$. Oceanogr., 2008, 64, 471.

11. T. Aoki, T. Nosaka, and M. Munemori, Bunseki Kagaku, 1987, 36, 717.

12. T. Aoki, T. Nosaka, and M. Munemori, J. Flow Injection Anal., 1987, 4, 15.

13. F. Maya, J. M. Estela, and V. Cerda, Anal. Chim. Acta, 2007, 601, 87.

14. J. L. Burguera and A. Townshend, Talanta, 1980, 27, 309.

15. J. Teckentrup and D. Klockow, Talanta, 1981, 28, 653.

16. X. X. Qian, Y. Y. Guo, M. Yamada, E. Kobayashi, and S. Suzuki, Talanta, 1989, 36, 505.

17. A. Safavi and M. A. Karimi, Talanta, 2002, 57, 491.

18. M. Ishii, M. Miura, and J. Sato, Bunseki Kagaku, 1992, 41, 157.

19. K. Fujimori, W. Ma, T. Moriuchi-Kawakami, Y. Shibutani, N. Takenaka, H. Bandow, and Y. Maeda, Anal. Sci., 2001, 17, 975 .

20. M. Yamada, T. Nakada, and S. Suzuki, Anal. Chim. Acta, 1983, 147, 401.

21. S. A. Al-Tamrah, A. Townshend, and A. R. Wheatley, Analyst, 1987, 112, 883.

22. J. L. Adcock, P. S. Francis, and N. W. Barnett, J. Fluoresc., 2009, $19,867$.

23. J. L. Adcock, P. S. Francis, and N. W. Barnett, Anal. Chim. Acta, 2009, 652, 303.

24. S. Mohr, J. M. Terry, J. L. Adcock, P. R. Fielden, N. J. Goddard, N. W. Barnett, D. K. Wolcott, and P. S. Francis, Analyst, 2009, 134, 2233.

25. H. Elderfield and A. Schultz, Annu. Rev. Earth Planet. Sci., 1996, 24, 191.

26. K. Kishida, Y. Sohrin, K. Okamura, and J. Ishibashi, Earth Planet. Sci. Lett., 2004, 222, 819.

27. T. Slezak, J. M. Terry, P. S. Francis, C. M. Hindson, D. C. Olson, D. K. Wolcott, and N. W. Barnett, Anal. Chem., 2010, 82, 2580.

28. S. Q. Lang, D. A. Butterfield, M. D. Lilley, H. P. Johnson, and J. I. Hedges, Geochim. Cosmochim. Acta, 2006, 70, 3830 .

29. J. L. Adcock, P. S. Francis, and N. W. Barnett, Anal. Chim. Acta, 2007, 601, 36

30. JIS K 0102. 17, "Chemical Oxygen Demand Using Potassium Permanganate at $100^{\circ} \mathrm{C}$ ", 2008, Japanese Industrial Standards Committee, Tokyo. 